[Hall, C. (1997). The National Qualifications Framework in 1996 and Beyond: A Call for Reflection on the Nature of Outcomes-Based Education. New Zealand Annual Review of Education, 6, 71-87]

\section{The National Qualifications \\ Framework in 1996 and Beyond: A \\ Call for Reflection on the Nature of Outcomes-Based Education}

\author{
CEDRIC HALL
}

\section{Abstract:}

This paper examines the concept of outcomes-based education, identified in the 1996 Report of the Tertiary Action Group, and underpinning the joint Ministry of Education and NZQA announcement that all provider qualifications be specified in terms of learning outcomes. It argues that the interpretation of an outcome cannot be separated from the educational processes that generate it. Furthermore, the point is made that students are likely to find information about the content and processes of a course just as useful for giving them a sense of direction for their learning as a statement of intended outcomes. Universities are cautioned that the outcomes-based model of education being promoted by the Ministry and NZQA might simply be a competency model in another guise.

$\mathrm{T}$ his paper presents a university perspective on the evolving concept of outcomes-based education, as evidenced by two developments in 1996 relating to the National Qualifications Framework (NQF):

- the report of the Tertiary Action Group (TAG, 1996), which recommended that all qualifications and their component parts be expressed in terms of learning outcomes;

- the joint announcement by the Ministry of Education and the New Zealand Qualifications Authority (NZQA) ${ }^{1}$ that, under the new NQF regime, provider qualifications would need to meet three criteria: (i) have level and credit specificity; (ii) provide an assurance of quality; and (iii) have clearly specified outcomes.

Taken together, the TAG report (1996) and the joint Ministry of Education and NZQA announcement represent a significant softening of the stand adopted by NZQA on its requirement that all senior secondary, tertiary and vocational qualifications be specified in terms of unit standards (NZQA, 1995). This shift in stance no doubt reflects the growing opposition from educationists in universities, polytechnics and secondary schools to the unit standard model and its perceived limitations. The appointment of the Honourable Wyatt Creech as Minister of Education, followed by the resignation in October of David Hood (the first CEO of NZQA), both provide further evidence that a less doctrinaire approach to the implementation of the National Qualifications Framework is imminent.

This paper examines exactly what a learning outcome provides, in order to challenge some of the thinking underpinning both the TAG report and the joint Ministry of Education and NZQA announcement. The conclusion reached is that the interpretation of outcomes cannot be separated sensibly from the educational processes that generate these outcomes. While the aim here is not to revisit old ground and offer yet another critique of the unit standard methodology, some of the points raised here are relevant to that approach. Papers by Elley (1995; 1996), Hall (1994; 1995a; 1995b; 1996), and Irwin (1994) cover the main issues.

This paper assumes some familiarity with the structure of the NQF and the nature and composition of its unit standards, and an awareness of the distinction between provider and national degrees as set down in the reports of the Tertiary Lead Group (TLG, 1994) and Tertiary Action Group.

\section{The Joint Ministry of Education and NZQA Announcement}

As indicated above, a joint Ministry of Education and NZQA announcement in May 1996 identified that, under the modified NQF regime, provider qualifications would be part of the future structure but would be required to meet the following "quality" criteria:

- have level and credit specificity;

- provide an assurance of quality;

- have clearly specified outcomes.

The TAG report, although preceding the joint announcement, identified many of the operational details by which these three criteria might be 
realised. For example, it defined the level and credit requirements for several qualifications (bachelors, honours, postgraduate certificate, postgraduate diploma, masters and $\mathrm{PhD}$ ); in respect of quality assurance, it provided criteria for approval and accreditation; and in respect of outcomes, it recommended that provider qualifications be specified in terms of learning outcomes both at the programme and component levels. The report elaborates the criteria in turn, but its principal emphasis was on the requirement that all qualifications be specified in terms of outcomes.

\section{Level and Credit Specificity}

Most educationists are likely to be sympathetic to the notion that some form of "currency translation" be adopted by each educational provider which would enable transferring students to understand more clearly the extent to which their previous learning has been recognised. Indeed, an appendix to the TAG report (1996) sets out some useful guidelines on credit transfer which all tertiary institutions would find helpful in administering their credit transfer systems. However, the translation of university systems based on 300, 108 or 42 credits/points to the 360-point NQF scale is by no means a simple task, especially when such systems do not share the same concepts, either of the unit of measurement itself, or of its nature. For example, universities do not accept that the stated outcomes in a unit standard are a sufficient basis for credit transfer information about the content and context in which these outcomes are embedded is considered essential.

The problems of adopting a currency translation become even more complicated when attempts are made to reconcile requirements (such as the TAG minimum of 72 NQF credits at each level of a bachelors degree) with a university philosophy that emphasises the composition of the whole degree. The former approach is quantitative and somewhat mechanistic, the latter more qualitative and related to programme philosophy, progression and coherence. The universities argue that the system of levels and credits used by an institution should be its own responsibility, and that these ought not to be tied to superficial (and generally unworkable) definitions associated with a central framework. However, it is not unreasonable to ask each institution to make explicit, with an appropriate rationale, the basis by which it translates NQF credits to its own system, and the basis by which decisions on credit transfer and recognition of prior learning (RPL) are to be made. It should be noted that both the TLG (1994) and
TAG reports recommended that final decisions on transfer be the business of the institutions themselves - the joint announcement that institutions make transparent their system of translation seems reasonable and acceptable.

\section{Quality Assurance}

The requirement of quality assurance - that a provider must demonstrate its capacity to deliver its educational programmes - is unlikely to be problematic for most universities and polytechnics, as long as the requirement does not impose restrictions on academic autonomy. The established systems of programme approval operated by the New Zealand Vice-Chancellors' Committee (NZVCC) and NZQA are capable of ensuring that educational programmes are well designed and resourced. The internal quality systems of institutions should ensure that courses, teaching, learning support and assessment are monitored and reviewed in line with good quality management practices. Systems such as academic audit provide a further layer of quality monitoring to support the internal operations of institutions. However, if the recommendations of the TAG report are to be the basis for a harmonisation of vocational and general education in the tertiary sector, then further work is clearly needed in bringing the universities and NZQA together. From the universities' perspective, the TAG recommendations are still too prescriptive in areas such as nomenclature, degree definitions, approval procedures, and the mechanism by which the NZQA and NZVCC systems are monitored (CUAP, 1996). The universities believe that an effective framework will be one which is based on a sound statement of principles, an acceptance of key definitions (e.g., for research, bachelors degree, etc.), and the absolute minimum of centralised rules and recording of information. As pointed out by the NZVCC Committee on University Academic Programmes (CUAP):

The universities are concerned that resources should be employed as economically and productively as possible. They resist a system which could involve large expenditure of both money and human resources in cumbersome administrative activity which is out of proportion to the educational benefit which might be derived from it. We are concerned that there should be a minimum of bureaucracy which could impinge on research and teaching. (CUAP, February, 1996) 


\section{Outcomes-Based Education}

In previous critiques of the NQF (Hall, 1994; 1995a; and 1996) it was pointed out that the educational core of a unit standard is no more than a statement of objectives, most of which are written as learning outcomes. This was demonstrated by showing the parallels between the educational core of a unit standard and traditional models of curriculum specification, in which the outcomes of a curriculum are stated in the form of behavioural objectives. The concept of an "outcomes-based" education system was not called into question. My objective here is not to dismiss the writing of learning outcomes as a useful device for giving students information, but to argue that learning outcomes are only a small piece in the quality assurance picture, and that unless we clarify what a learning outcome actually provides we will be at risk of adopting a form of competency-based education which is the unit standard model in another guise. Some of the recommendations and advice given by TAG on pages 10 and 42 of its report therefore need to be challenged (TAG, 1996).

\section{The distinction between objectives and outcomes}

The TAG report has drawn a distinction between an "objective" and an "outcome". The view presented is that an objective describes the "planned journey" (e.g., "a programme objective may be to introduce students to a range of theories") whereas a "learning outcome"

is used to describe an activity or set of activities that a person has been assessed as able to carry out against stated assessment criteria. The focus is on what a person is able to do as a result of undertaking the programme. (TAG, p. 10)

This distinction raises several issues:

- While acknowledging that any group is free to define terminology in any way that it finds meaningful, any other group must also be free to reject such terminology if it considers the usage to be inadequate for its own context. It is contended here that the distinction made by TAG is less robust and less useful than the one used, for example, by Victoria University of Wellington in its course handbook for staff. VUW defines an "objective" as ...

a succinct statement of intent which identifies an outcome to be achieved and/or a process to be undertaken or experienced.
In other words, for VUW an objective can take the form of an outcome, a process or a blend of each. The difference between the TAG and VUW views is summarised diagrammatically below:

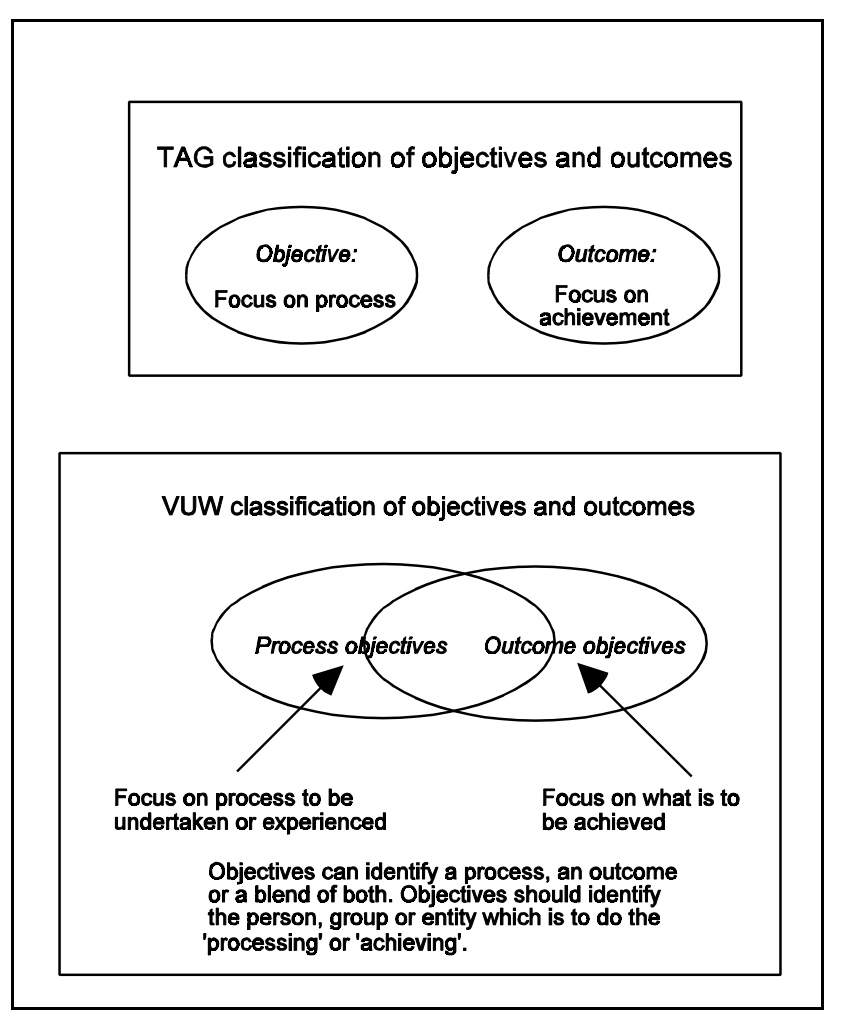

- The VUW classification recognises that often the distinction between a process and an outcome is blurred. For example, TAG would find it hard to explain clearly how the following "learning outcomes" for its definition of an honours programme differ from "process objectives":

Graduates will be able to:

- engage in self-directed learning;

- $\quad$ undertake study, research and scholarship in the principal subject(s) of the degree. (TAG, 1996, p. 25) 
Are these really outcomes? Are they not, in fact, processes which define what students will do during the course? Perhaps they are a blend of both.

Similarly, one of the outcome statements in the report for a "mock" provider degree in business identifies that graduates will

use skills of analysis, evaluation and critical thinking to

formulate solutions to accounting problems. (TAG,

1996, p. 55)

To what extent is this defining an outcome for the course, or defining the processes which students will engage in during the course? In practice, does it actually matter? The important point is that the objectives for a course, whether they are written in the form of processes, outcomes or a blend of both, should identify what is expected of students and help them see where the course will take them. There appears to be no research evidence to suggest that an objective stated in the form of an outcome is superior to an objective stated in the form of a process. If utility is the test, then it is very likely that students will want to know as much about the processes that they have to undertake or experience, as about the outcomes which are expected of them.

- The TAG classification of objectives and outcomes appears to associate "objectives" with the actions of teachers or programmes/ courses and "outcomes" with the actions of learners. The explanation given by TAG (p. 10) is not clear on this point. In fact, both process and outcome objectives can be written to describe or summarise course activities, the intent of teachers, or the expectations held of students. A well written objective will make it explicit who (or what) is the "subject" of the statement. The following examples illustrate this point.

Process objectives:

The teacher will monitor student attendance at tutorials during the course.

Students will be expected to contribute to tutorial discussions.

Tutorials will introduce students to the techniques of case study analysis.
Outcome objectives:

The teacher will return all marked work to students within three weeks.

Students will be able to construct a questionnaire for a political opinion poll.

Pass rates for this course will be increased by $10 \%$ without the lessening of standards.

The distinction made by TAG between an objective and an outcome is a superficial analysis of the relationship, and fails to consider what is most useful for students. It ought not to be accepted.

\section{The Association of Assessment Criteria with Learning Outcomes}

The advice given by TAG that, "Each learning outcome should be amplified by assessment criteria which state the evidence and quality of evidence needed so a judgement can be made that the outcome has been achieved" should also be rejected. It simply re-creates the unit standard format of associating performance criteria with each individual element (learning outcome). The intention of TAG may have been different, but the spectre of the unit standard model is plainly apparent in the description given. This issue has been dealt with comprehensively in earlier papers (Hall, 1994, 1995c; NZVCC, 1994).

Under the NZQA approach, performance criteria are associated and registered with the elements in a unit standard. The comparable approach in university education would be to require performance criteria to be listed in turn with each objective or learning outcome. This raises a pedagogical question over the best place to list such criteria; the argument here is that many of the performance criteria currently being registered with unit standards for the Framework are of little use - they are too vague and far removed from the tasks that students undertake. Furthermore, in their present format, they provide encouragement for providers to develop assessment procedures which check off each objective in isolation - a checklist mentality is fostered. As already argued, learning and teaching should be directed towards both the acquisition and integration of knowledge, skills and values. This suggests that assessment criteria should be associated with the tasks that students undertake (exams, essays, reports, projects, etc.) and that these tasks should be structured so that the different 
learning objectives can be sensibly integrated through intellectual processes such as composition, argument, design, problem-solving and research.

Note that the argument here is not about whether performance criteria should be stated, but rather over what point in the process these criteria should be made explicit to students. Pedagogically, it makes most sense to relate the criteria to the tasks students are set - this is where the criteria are most likely to be understood by students and taken account of.

In defence of the NZQA, it should be stated that their advisers discourage providers from developing a checklist approach to assessment in contexts which call for an integrated approach. Perhaps, however, this highlights the superficiality of trying to specify performance criteria too early in the course design process. (Hall, 1995c, pp. 164-5)

The association of assessment (performance) criteria individually with each objective should be rejected by universities. However, the universities should continue to stress the importance of giving students clear information about the objectives (outcomes and processes) of a course and the basis by which these are embedded in particular assessment tasks. In line with the above extract, it follows that students should be given clear information about the performance criteria by which they will be judged.

\section{The generality/specificity of objectives}

Equally unacceptable is the advice given by TAG that, "Learning outcomes for a course should be specified at a level that does not require them to be revised annually." It is possible that TAG have confused considerations which relate to registration of information on the Framework, with what is appropriate information for teachers to include in their course outlines. In fact, TAG have crossed the boundary between what is their business to recommend and what should be left to providers and their teachers to decide. When preparing their course outlines, academics are well advised to write the objectives at a level which students at the beginning of a course can understand, so that they can see where the course will take them. The level of generality/ specificity of objectives is up to the teacher to decide, based on the nature of the subject, the particular approach to be adopted, the background of the students, and the assessment framework that will be used. Consideration of whether or not the objective will be able to be used in the following year is of little importance.

If TAG were concerned about registration of information on the Framework, then stability over time could well be a consideration. In a recent conference paper given in South Africa, the following registration principle was recommended:

In developing procedures for approving programmes, pay close attention to the principle stated earlier in this paper: that registration of qualifications should involve the minimum of information needed to explain what a qualification is about, its structure, and who it is for; and that the information registered should be at a level of detail where what is recorded will not need frequent amendment. For university programmes, I believe that the emphasis should be on the total programme, not on the detail of the components. (Hall, 1996, pp. 296-297)

Within a university context, what is important is what to register at the programme level. The purpose of a programme, its major objectives, its basic structure, who it is intended for, and the capacity of the institution to deliver it, are what should be considered during the approval process. Information about the content and objectives of individual courses should be such that it gives the programme approvers enough information to judge the overall coherence of the offering. However, approval procedures must recognise that the courses within a programme will evolve to take account of changes in knowledge, changes in emphasis from year to year, the need for course content to be responsive to community and professional needs, and changes of staff who bring different perspectives to a subject. This necessarily means that the objectives for a course must be allowed to vary from year to year. What we have is a clash between two purposes: to provide enough information so that programme approval can operate effectively, and to allow courses the freedom to adapt to a changing environment. The advice, "Learning outcomes for a course should be specified at a level that does not require them to be revised annually" does not solve this problem, because it fails to handle the dynamic aspects of a course. Instead of being prescriptive on this point, TAG would have been better advised to acknowledge the significant role of institutions in ensuring that changes to the objectives of their programmes and courses are carefully monitored. 


\section{The availability of component objectives at the time of approval}

On page 42 of the TAG Report (1996), the recommendation is made that the learning outcomes of component parts should be available at the time of approval, but will not be registered on the Framework. This appears to be an attempt at a compromise between sufficiency of information for approval and recognition of the need to allow courses room for change over time. But, surely, any objectives which are available at the time of approval should be labelled as "indicative only". First, as already argued, approval needs to recognise that course objectives will change over time. Secondly, TAG needs to recognise that final CUAP approval takes place six or seven months before a new course is first offered. This time frame allows for expert staff to be appointed and for these people to undertake the detailed development of new courses or the adaptation of existing courses. This process is almost certain to result in significant revisions of the objectives for some of the courses. Thirdly, we need to be certain that new staff do not feel compelled to follow objectives simply because they appear to carry the authority of centralised approval. The best procedure for dealing with changes to a course would appear to be to locate the relevant approval mechanisms within institutions and as near to the delivery as is practical. Through processes such as academic audit, institutions can be challenged on how they implement this.

A final comment on the approval of objectives: it is a moot point whether availability of component objectives is actually necessary for making a judgement on whether or not the structure of a programme is soundly based. Certainly, information is needed which identifies the domain of the component papers and how these link to the overall purpose and objectives of the programme. The best form of this information will not always be a statement of objectives. An example would be the qualification specification for a Postgraduate Diploma in Tertiary, Continuing and Community Education described in Hall (1995b). This specification identifies the objectives for the qualification, but not the component papers. However, a grid on the second page shows clearly how each paper relates to the programme objectives. In respect of two of the papers it would be difficult to identify meaningful objectives since they require students to negotiate a focus of particular relevance to their own context. The specification of objectives is part of the course process.

\section{A further comment on the utility of objectives for students}

The TAG definition of a learning outcome appears not to recognise the very important, if not obvious, distinction between a "statement of learning outcomes" (the intended outcomes) and the actual learning that occurs during a programme or course. The former is an attempt to encapsulate at the outset of a course what is expected of students; it identifies the direction that the learning should take, but it rarely describes in detail or with precision what a learner is expected to achieve. Consider the following set of objectives (in outcome form) for a course in educational research methods:

Students passing this course should be able to:

1. Explain the relative strengths and limitations of different research paradigms;

2. Evaluate the quality of a given research study;

3. Construct questionnaires and other survey instruments;

4. Conduct an interview for a survey;

5. Analyse data using quantitative and qualitative methods;

6. Design (not conduct) a research study on a topic of their own choice.

At a superficial level, the above outcomes identify what students should be able to do. However, exactly what is achieved by the end of the course will vary considerably, depending on a number of factors. For example, in relation to the content of the course, what research paradigms will be covered, and to what depth? What kinds of research studies will be evaluated? What types of questionnaires and survey instruments will be covered? What kinds of interviews will be conducted, and by what medium? What quantitative and qualitative methods will be covered, and to what depth? And so on. It is evident we need to know a lot more about the content of the course before we can make informed interpretations of what a student is expected to know or do.

Similarly, we know that students will vary considerably in respect of their understanding of the content and in their ability to demonstrate the related skills. Most will pass, some will do so narrowly, others will demonstrate excellence. The open-ended nature of knowledge and learning is something which a statement of learning outcomes can never capture with precision. 
All of this might seem fairly obvious, but the obvious sometimes gets lost in the euphoria for a particular approach. Learning outcomes are useful for giving students a sense of direction; they are much less useful in describing with precision what a student will achieve. If utility is the test, it is very likely that students will find a statement about the course content and processes just as valuable for giving them the direction they need.

A final observation: the above statement of learning outcomes probably represents around 200 hours of student activity and learning; yet the statement takes less than 30 seconds to read! In 30 seconds, it is impossible to capture the richness and diversity of 200 hours of educational experience and learning. There is a danger of becoming too carried away with what a statement of learning outcomes actually tells. If we are interested in clarity of information, content and process are as important as outcomes. The form in which we give students information is less important than the quality of that information.

The message from the preceding discussion is very clear. Outcomes depend on processes for their particular meaning and interpretation. A system of qualifications which gives emphasis to outcomes over processes fails to understand the inextricable link between the two. This has particular relevance for models of standard setting (e.g., unit standards) which separate the specification of standards from the development of curricula. While such a separation may make sense in some industrial training areas, it has only a limited application in general and professional education.

\section{Philosophical underpinnings of outcomes-based education}

The support for an outcomes-based educational policy comes not only from NZQA and TAG but also from the Ministry of Education - as evidenced in a Cabinet Committee paper (Ministry of Education, 1996) released under the Official Information Act. It would be helpful if these three bodies were able to identify the research basis for this decision, or to explain the philosophical underpinnings. To base an entire national educational structure on such a foundation surely requires a solid research and/or philosophical basis which is consistent with every level and form of education to be linked with the NQF. Some industry groups which operate within a highly specified knowledge and skills domain might well choose this approach for defining the competencies expected of their trainees. But why is this approach uniformly appropriate for subjects such as history, mathematics, English, drama and science, or for professions such as teaching, accountancy, law and architecture? For a particular educational approach to be adopted nationally, it must be demonstrably the most suitable way forward for all levels of education, all subject and professional areas, and all qualifications to which it is intended to relate. Relevance must be demonstrated both within and across all subjects and professions and for all forms of education.

If the basis of the outcomes requirement is simply to ensure that students receive clear information about what is expected of them, and to enable them to make choices about what to study, then the approach should emphasise clarity of information, not the form of that information. The specification of outcomes, while helpful, is only part of the picture that students seek. Most importantly, we need to rely on the professionalism of our teachers to give clear and appropriate information to students, to design effective courses, and to follow sound assessment principles. Institutions should support this with an appropriate range of quality systems.

It may be naive to suppose that the outcomes requirement is simply about giving students clear information. The requirement, of course, is firmly rooted in the competency-based model of education promoted by NZQA and the technocratic conception of education that accompanies this approach (See, for example, Irwin, 1994; Codd et al., 1995; Elley, 1995; and Codd, 1995). This is illustrated by four short extracts from the Cabinet Committee paper mentioned previously [emphasis added]:

Inherent in the policy was a desire to move away from a time-served system to one which recognised competencies.

Quality Information: It should provide high quality and accurate information about individuals' competencies, and reduce information costs.

The structure of the NQF sees these standards classified by level (8 levels indicating the relative complexity of the competency being measured)

Greatest portability would be achieved if the competencies which make up a qualification were defined in a universally-accepted common currency.

There would appear to be enough evidence in these extracts to suggest that the underlying thinking behind the outcomes-based conception is 
actually a competency approach to education. The Ministry of Education may possibly be using the term competency loosely to mean "standards-based". If so, this is inviting confusion, since "competency" is normally associated with a pass-fail assessment of student performance (e.g. the unit-standard methodology). A number of writers (e.g., Elley, 1995; Hall, 1994; Irwin, 1994) have argued that competencybased assessment is an inappropriate model for most academic subjects and for substantial areas of professional education.

The broader concept of "standards-based" education is a rather different one, and one which is able to be met in a relatively low-key way by tertiary institutions through applying good assessment practices. These include: giving students clear information about the objectives of a course (processes and outcomes); designing assessment tasks which directly relate to these objectives; specifying the assessment criteria which will be used to judge student work on these tasks; giving this information to students before they undertake their work; taking steps to ensure that different teachers and markers apply the criteria as consistently as possible (this may involve training of markers and moderation of grades); and giving students useful feedback on their performance. However, these practices need to recognise all of the following points:

- the specification of clearly defined performance standards, including assessment criteria, is extremely difficult in most educational contexts - NZQA, TAG and the Ministry of Education have been slow to acknowledge this point;

- the development and/or application of educational standards inevitably involves some element of norm-referenced assessment (see, for example, Elley, 1995);

- the place in the procedure where standards become most explicit (in as far as they do become explicit) is in association with assessment tasks, not the course objectives;

- the effort and cost needed in making clear an educational standard quickly reaches a point where the law of diminishing returns takes over - additional effort is not matched by educational benefits.

A further point should be made: if flexibility in course design and delivery is to be a genuine feature of membership of the Framework, then providers should be given maximum freedom to develop and monitor their own educational standards. Registration on the Framework should be mainly about agreement on definitions, nomenclature and quality assurance, not about educational approach. Innovation will flourish in an open-ended teaching and learning structure, not on one which is based on highly prescriptive and centralised statements of learning outcomes. More appropriate processes, such as academic audit, are available to monitor how institutions determine and assure the quality of their education.

\section{Note}

1. NZQA/MOE joint briefing meeting with representatives from tertiary education sector providers, held at the MOE, April, 1996.

\section{References}

Codd, J., McAlpine, D., \& Poskitt, J. (1995). Assessment policies in New Zealand: Educational reform or political agenda? In R. Peddie \& B. Tuck(Eds.), Setting the standards. Palmerston North: Dunmore Press.

Codd, J. (1995). NZQA and the politics of centralism. Paper presented at the Annual Conference of the NZ Association for Research in Education, Massey University, Palmerston North, December 7-10, 1995.

Committee on University Academic Programmes (CUAP). (1996). Tertiary Action Group: Universities' response to second draft of consultation papers. Wellington: NZVCC.

Elley, W. (1995). What is wrong with standards-based assessment? In R. Peddie \& B. Tuck (Eds.), Setting the standards. Palmerston North: Dunmore Press.

Elley, W. (1996). Unresolved issues in fitting academic courses into the Qualifications Framework. Delta, 48(1), 101-112.

Hall, C. (1994). Obstacles to the integration of university qualifications and courses into the National Qualifications Framework. Higher Education in New Zealand: Occasional Paper No 1. Wellington: Syndicate of Educational Development Centres of New Zealand.

Hall, C. (1995a). Why universities do not want unit standards. NZVCC Newsletter, 35, 5-8.

Hall, C. (1995b). Following principles which accord with the National Qualifications Framework, but without unit standards. Victoria University of Wellington: University Teaching Development Centre. 
Hall, C. (1995c). University qualifications and the New Zealand National Qualifications Framework: Obstacles and a way forward. In R. Peddie \& B. Tuck (Eds.), Setting the standards. Palmerston North: Dunmore Press.

Hall, C. (1996). Blending academic standards with the New Zealand National Qualifications Framework: Lessons for other countries. In A. H. Strydom, L. O. K. Lategan, \& A. Muller (Eds.), Quality assurance in South African higher education: National and international perspectives. Bloemfontein: Unit for Research into Higher Education, University of the Orange Free State.

Irwin, M. (1994). Curriculum, assessment and qualifications: An evaluation of current reforms. Wellington: Education Forum.

Ministry of Education. (1996). The National Qualifications Framework. Cabinet Committee Paper, ETE(96)4.

New Zealand Qualifications Authority. (1995). Proposed legislation changes: NZQA. Submission to the Cabinet Committee on Education, Training and Employment, Wellington.

New Zealand Vice-Chancellors' Committee. (1994). The National Qualifications Framework and the universities. NZVCC: Wellington.

Tertiary Action Group. (1996). Report to the Board of the New Zealand Qualifications Authority on the implementation of a harmonised Qualifications Framework. Wellington, New Zealand Qualifications Authority.

Tertiary Lead Group. (1994). A single harmonised qualifications framework. Report of the Ministerial Tertiary Lead Group, Wellington.

\section{The author}

Cedric Hall is Professor and Dean of Education at Victoria University of Wellington, and a former Director of the University Teaching Development Centre. His research interests include course design, teaching, learning, assessment and evaluation. Some of his recent papers have focussed on quality assurance in higher education and developments in the National Qualifications Framework. 